\title{
Disparities in COVID-19 Vaccination Status, Intent, and Perceived Access for Noninstitutionalized Adults, by Disability Status - National Immunization Survey Adult COVID Module, United States, May 30-June 26, 2021
}

\author{
A. Blythe Ryerson, $\mathrm{PhD}^{1}$; Catherine E. Rice, $\mathrm{PhD}^{1}$; Mei-Chuan Hung, $\mathrm{PhD}^{2,3,4}$; Suchita A. Patel, DO 2,3 ; Julie D. Weeks, PhD \\ Jennifer L. Kriss, PhD ${ }^{2,3}$; Georgina Peacock, MD ${ }^{1}$; Peng-Jun Lu, MD ${ }^{2,3}$; Amimah F. Asif, MPH ${ }^{2,3}$; Hannah L. Jackson, PhD ${ }^{2}$; James A. Singleton, PhD ${ }^{2,3}$
}

Estimates from the 2019 American Community Survey (ACS) indicated that $15.2 \%$ of adults aged $\geq 18$ years had at least one reported functional disability (1). Persons with disabilities are more likely than are those without disabilities to have chronic health conditions (2) and also face barriers to accessing health care (3). These and other health and social inequities have placed persons with disabilities at increased risk for COVID-19-related illness and death, yet they face unique barriers to receipt of vaccination $(4,5)$. Although CDC encourages that considerations be made when expanding vaccine access to persons with disabilities, ${ }^{*}$ few public health surveillance systems measure disability status. To describe COVID-19 vaccination status and intent, as well as perceived vaccine access among adults by disability status, data from the National Immunization Survey Adult COVID Module (NISACM) were analyzed. Adults with a disability were less likely than were those without a disability to report having received $\geq 1$ dose of COVID-19 vaccine (age-adjusted prevalence ratio $[\mathrm{aPR}]=0.88 ; 95 \%$ confidence interval $[\mathrm{CI}]=0.84-0.93$ ) but more likely to report they would definitely get vaccinated $(\mathrm{aPR}=1.86 ; 95 \% \mathrm{CI}=1.43-2.42)$. Among unvaccinated adults, those with a disability were more likely to report higher endorsement of vaccine as protection $(\mathrm{aPR}=1.29$; $95 \% \mathrm{CI}=1.16-1.44)$, yet more likely to report it would be or was difficult to get vaccinated than did adults without a disability $(\mathrm{aPR}=2.69 ; 95 \% \mathrm{CI}=2.16-3.34)$. Reducing barriers to vaccine scheduling and making vaccination sites more accessible might improve vaccination rates among persons with disabilities.

Data from noninstitutionalized adults aged $\geq 18$ years were collected in the NIS-ACM by telephone interview during May 30-June 26, 2021 using a random-digit-dialed sample of cellular telephone numbers, stratified by locality. ${ }^{\dagger}$ Although the current U.S. Department of Health and Human Services (HHS) minimum standard for measuring disability in surveys

\footnotetext{
*COVID-19 Vaccine Recommendations and Guidelines of the Advisory Committee on Immunization Practices, CDC. https://www.cdc.gov/vaccines/ hcp/acip-recs/vacc-specific/covid-19.html

$\dagger$ The NIS-ACM cellular telephone sample was stratified by state, the District of Columbia, five local jurisdictions (Bexar County, Texas; Chicago, Illinois; Houston, Texas; New York City, New York; and Philadelphia County, Pennsylvania), and Guam, Puerto Rico, and the U.S. Virgin Islands.
}

relies on six questions (6), during the COVID-19 emergency response, data collection opportunities were limited. To assess COVID-19 vaccination status for this demographic group, CDC added a single question to the NIS-ACM: "Do you have serious difficulty seeing, hearing, walking, remembering, making decisions, or communicating?" Respondents who answered "yes" were considered to have a disability, and those who answered "no" were categorized as having no disability. Among all respondents $(56,749 ; 18.9 \%$ final response rate), 5,361 (9.4\%) reported having a disability, and 51,253 (90.3\%) reported no disability. Disability status was missing for $135(0.2 \%)$ respondents, and these respondents were excluded from all analyses. Respondents were also asked a series of questions on perceived COVID-19 risk, current COVID-19 vaccination status, and attitudes and perceived barriers to getting vaccinated. $\$$

All percentages were weighted to represent the noninstitutionalized U.S. adult population. Survey weights were calibrated to state-level vaccine administration data reported to CDC as of June 15, 2021.9 T-tests were performed to detect differences in percentages between groups. Unadjusted and age-adjusted vaccination prevalence ratios (PRs) comparing percentages of adults with a disability with those without a disability were calculated using logistic regression and predictive marginals. T-tests and PRs were considered statistically significant if $\mathrm{p}$-values were $<0.05$. All analyses were performed using SAS (version 9.4; SAS Institute) and SUDAAN (version 11.0.3; Research Triangle Institute). This activity was reviewed by CDC and was conducted consistent with applicable federal law and CDC policy.**

Among all respondents, 9.4\% reported having a disability. In age-adjusted analyses, adults with a disability were less likely than were those without a disability to report having received $\geq 1$ dose of a COVID-19 vaccine $(\mathrm{aPR}=0.88 ; 95 \% \mathrm{CI}=0.84-0.93)$ (Table) but more likely to report they would definitely get vaccinated $(\mathrm{aPR}=1.86 ; 95 \% \mathrm{CI}=1.43-2.42)($ Supplementary Table 1 ,

\footnotetext{
${ }^{\S}$ https://www.cdc.gov/vaccines/imz-managers/nis/downloads/NIS-ACMQuestionnaire-Q2-2021_508.pdf

9 Additional information about the NIS-ACM is available at https://www.cdc gov/vaccines/imz-managers/nis/about.html\#current-surveys.

** 45 C.F.R. part 46; 21 C.F.R. part 56; 42 U.S.C. Sect. 241(d); 5 U.S.C. Sect. 552a; 44 U.S.C. Sect. 3501 et seq.
} 


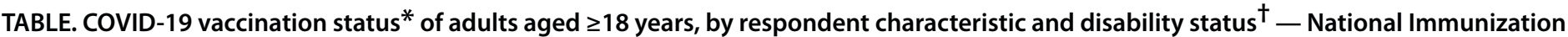
Survey Adult COVID Module, United States, May 30-June 26, 2021

\begin{tabular}{|c|c|c|c|c|c|c|}
\hline \multirow[b]{2}{*}{ Respondent group/Characteristic } & \multicolumn{2}{|r|}{ With a disability ${ }^{\dagger}$} & \multicolumn{2}{|c|}{ Without a disability } & \multicolumn{2}{|c|}{ Prevalence ratio $§(95 \% \mathrm{Cl})$} \\
\hline & No. & $\%$ " Vaccinated* $(95 \% \mathrm{Cl})$ & No. & $\%$ "Vaccinated* $(95 \% \mathrm{Cl})$ & Unadjusted & Age-adjusted \\
\hline Total & 5,345 & $66.7(63.9-69.3)$ & 51,106 & $64.5(63.5-65.4)$ & $1.03(0.99-1.08)$ & $0.88(0.84-0.93)^{* *}$ \\
\hline \multicolumn{7}{|l|}{ Age group, yrs } \\
\hline $18-24$ (Ref) & 198 & 33.5 (23.8-44.7) & 5,015 & $46.4(43.9-49.0)$ & $0.72(0.52-0.99)^{* *}$ & NA \\
\hline $25-29$ & 162 & $35.5(22.9-50.6)$ & 4,203 & $49.8(46.7-52.9)$ & $0.71(0.48-1.07)$ & NA \\
\hline $30-39$ & 372 & $48.8(40.2-57.5)^{\dagger \dagger}$ & 8,817 & $52.9(50.8-55.0)^{\dagger \dagger}$ & $0.92(0.77-1.11)$ & NA \\
\hline 40-49 & 559 & $54.4(46.2-62.3)^{\dagger \dagger}$ & 8,050 & $60.8(58.4-63.1)^{\dagger \dagger}$ & $0.89(0.77-1.04)$ & NA \\
\hline $50-64$ & 1,783 & $62.8(57.6-67.7)^{\dagger \dagger}$ & 14,246 & $71.9(70.1-73.6)^{\dagger \dagger}$ & $0.87(0.80-0.95)^{* *}$ & NA \\
\hline $65-74$ & 1,260 & $82.7(77.4-87.0)^{\dagger \dagger}$ & 7,069 & $88.6(86.6-90.4)^{\dagger \dagger}$ & $0.93(0.88-0.99)^{* *}$ & NA \\
\hline$\geq 75$ & 953 & $88.2(83.7-91.6)^{\dagger \dagger}$ & 2,827 & $90.0(87.5-92.1)^{\dagger \dagger}$ & $0.98(0.93-1.03)$ & NA \\
\hline \multicolumn{7}{|l|}{ Sex } \\
\hline Male (Ref) & 2,542 & $66.4(62.2-70.5)$ & 25,297 & $61.9(60.6-63.2)$ & $1.07(1.00-1.15)^{* *}$ & $0.91(0.85-0.99)^{* *}$ \\
\hline Female & 2,747 & $67.3(63.6-70.7)$ & 25,457 & $67.0(65.7-68.3)^{\dagger \dagger}$ & $1.00(0.95-1.06)$ & $0.86(0.80-0.92)^{* *}$ \\
\hline \multicolumn{7}{|l|}{ Race/Ethnicity ${ }_{\S}$} \\
\hline White (Ref) & 2,993 & $69.0(65.4-72.4)$ & 30,871 & $66.6(65.5-67.7)$ & $1.04(0.98-1.09)$ & $0.88(0.82-0.94)^{* *}$ \\
\hline Hispanic & 822 & $67.2(59.8-73.7)$ & 6,613 & $61.8(59.2-64.3)^{\dagger \dagger}$ & $1.09(0.97-1.22)$ & $0.94(0.84-1.05)$ \\
\hline Black & 726 & $60.1(52.8-67.1)^{\dagger \dagger}$ & 5,748 & $56.3(53.6-58.9)^{\dagger \dagger}$ & $1.07(0.94-1.22)$ & $0.84(0.73-0.97)^{* *}$ \\
\hline $\mathrm{Al} / \mathrm{AN}$ & 105 & $38.2(23.6-55.2)^{\dagger \dagger}$ & 538 & $39.2(31.8-47.1)^{\dagger \dagger}$ & $0.97(0.81-1.56)$ & $0.85(0.56-1.30)$ \\
\hline Asian & 127 & 74.7 (46.5-90.9) & 3,015 & $85.5(81.5-88.8)^{\dagger \dagger}$ & $0.87(0.64-1.19)$ & $0.86(0.67-1.12)$ \\
\hline NHPI & 113 & $71.1(27.8-94.0)$ & 974 & $59.1(47.0-70.2)$ & $1.20(0.68-2.13)$ & $0.78(0.32-1.91)$ \\
\hline Multiple race/Other & 294 & $55.6(43.0-67.6)^{\dagger \dagger}$ & 1,797 & $49.2(43.9-54.5)^{\dagger \dagger}$ & $1.13(0.88-1.45)$ & $0.85(0.62-1.18)$ \\
\hline \multicolumn{7}{|l|}{ Urbanicity } \\
\hline MSA, principal city (Ref) & 1,387 & $68.7(62.8-74.0)$ & 14,609 & $68.0(66.2-69.7)$ & $1.01(0.93-1.10)$ & $0.88(0.79-0.97)^{* *}$ \\
\hline MSA, nonprincipal city & 2,697 & $67.4(63.7-70.9)$ & 26,796 & $65.1(63.9-66.3)^{\dagger \dagger}$ & $1.04(0.98-1.10)$ & $0.89(0.84-0.95)^{* *}$ \\
\hline Non-MSA & 1,261 & $61.4(55.4-67.2)$ & 9,701 & $54.4(52.0-56.7)^{\dagger \dagger}$ & $1.13(1.02-1.26)$ & $0.88(0.77-1.01)$ \\
\hline \multicolumn{7}{|l|}{ SVI of county of residence ${ }^{* * *}$} \\
\hline Low (Ref) & 1,225 & $68.0(62.3-73.2)$ & 14,066 & $69.9(68.2-71.6)$ & $0.97(0.89-1.06)$ & $0.84(0.76-0.93)^{* *}$ \\
\hline Moderate & 1,687 & $68.6(63.6-73.2)$ & 17,064 & $65.1(63.5-66.6)^{\dagger \dagger}$ & $1.05(0.98-1.14)$ & $0.90(0.83-0.99)^{* *}$ \\
\hline High & 1,520 & $64.8(59.8-69.4)$ & 11,864 & $60.4(58.6-62.2)^{\dagger \dagger}$ & $1.07(0.99-1.16)$ & $0.89(0.82-0.98)^{* *}$ \\
\hline \multicolumn{7}{|c|}{ Poverty status and household income ${ }^{\dagger+\dagger}$} \\
\hline Above poverty, $\geq \$ 75 k$ (Ref) & 798 & $78.0(70.3-84.1)$ & 19,539 & $72.5(71.0-73.9)$ & $1.08(0.98-1.17)$ & $0.97(0.87-1.07)$ \\
\hline Above poverty, $<\$ 75 k$ & 1,911 & $68.9(64.5-73.1)^{\dagger+}$ & 15,528 & $61.1(59.4-62.7)^{\dagger+}$ & $1.13(1.05-1.21)^{* *}$ & $0.94(0.86-1.03)$ \\
\hline Below poverty & 1,137 & $55.5(49.4-61.5)^{\dagger \dagger}$ & 4,410 & $48.6(45.6-51.7)^{\dagger \dagger}$ & $1.14(1.01-1.30)^{* *}$ & $0.95(0.83-1.07)$ \\
\hline Unknown income & 1,499 & $66.6(61.3-71.4)^{\dagger \dagger}$ & 11,629 & $64.3(62.4-66.2)^{\dagger \dagger}$ & $1.03(0.95-1.12)$ & $0.89(0.81-0.98)^{* *}$ \\
\hline
\end{tabular}

See table footnotes on the next page.

https:/stacks.cdc.gov/view/cdc/109902). Among unvaccinated adults, those with a disability were more likely than those without a disability to report they were very or moderately concerned about getting COVID-19 $(\mathrm{aPR}=1.61 ; 95 \% \mathrm{CI}=1.37-1.89)$, thought the vaccine is very or somewhat important for protection $(\mathrm{aPR}=1.29 ; 95 \% \mathrm{CI}=1.16-1.44)$, reported many or almost all friends and family members as vaccinated $(\mathrm{aPR}=1.19$; $95 \% \mathrm{CI}=1.03-1.38)$, and had a health care provider recommend the vaccine $(\mathrm{aPR}=1.27 ; 95 \% \mathrm{CI}=1.08-1.51)$ (Figure 1) (Supplementary Table 2, https://stacks.cdc.gov/view/ $\mathrm{cdc} / 109903)$.

Overall, adults with a disability were more likely than were those without a disability to report that it would be or was somewhat or very difficult to get vaccinated $(\mathrm{aPR}=1.19 ; 95 \% \mathrm{CI}=1.05-1.36)$, and this observation was more pronounced among the unvaccinated $(\mathrm{aPR}=2.69$; $95 \% \mathrm{CI}=2.16-3.34$ ) (Figure 2). Among unvaccinated adults, those with a disability were more likely than were those without a disability to report having the following difficulties associated with getting the vaccine: getting an appointment online $(\mathrm{aPR}=2.14 ; 95 \% \mathrm{CI}=1.48-3.10)$, not knowing where to get vaccinated $(\mathrm{aPR}=1.95 ; 95 \% \mathrm{CI}=1.36-2.79)$, getting to vaccination sites $(\mathrm{aPR}=3.43 ; 95 \% \mathrm{CI}=2.53-4.67)$, and vaccination sites not being open at convenient times $(\mathrm{aPR}=1.69 ; 95 \% \mathrm{CI}=1.23-2.33)$.

\section{Discussion}

COVID-19 vaccination coverage was lower among U.S. adults with a disability than among those without a disability, even though adults with a disability reported less hesitancy to getting vaccinated. Unvaccinated adults with disabilities were more likely than were those without a disability to report thinking that the vaccine is important protection, indicating that there might be potential for increasing vaccination coverage in this group. However, adults with a disability anticipated or experienced more difficulty obtaining a COVID-19 vaccination than did those without a disability. Reducing barriers to 
TABLE. (Continued) COVID-19 vaccination status* of adults aged $\geq 18$ years, by respondent characteristic and disability status ${ }^{\dagger}-$ National $^{*}$ Immunization Survey Adult COVID Module, United States, May 30-June 26, 2021

\begin{tabular}{|c|c|c|c|c|c|c|}
\hline \multirow[b]{2}{*}{ Respondent group/Characteristic } & \multicolumn{2}{|r|}{ With a disability ${ }^{\dagger}$} & \multicolumn{2}{|c|}{ Without a disability } & \multicolumn{2}{|c|}{ Prevalence ratio $\S(95 \% \mathrm{Cl})$} \\
\hline & No. & \%" Vaccinated* $(95 \% \mathrm{Cl})$ & No. & \%" Vaccinated* $(95 \% \mathrm{Cl})$ & Unadjusted & Age-adjusted \\
\hline \multicolumn{7}{|l|}{ Education level } \\
\hline College graduate (Ref) & 1,338 & $80.2(74.6-84.9)$ & 23,844 & $79.2(78.0-80.5)$ & $1.01(0.95-1.08)$ & $0.89(0.81-0.99)^{* *}$ \\
\hline Some college & 1,652 & $66.0(61.2-70.5)^{\dagger+}$ & 13,590 & $62.2(60.5-63.9)^{\dagger+}$ & $1.06(0.98-1.14)$ & $0.94(0.87-1.03)$ \\
\hline High school graduate or less & 2,175 & $62.6(58.4-66.6)^{\dagger \dagger}$ & 12,231 & $53.8(52.1-55.5)^{\dagger \dagger}$ & $1.16(1.08-1.25)^{* *}$ & $0.93(0.86-1.01)$ \\
\hline \multicolumn{7}{|l|}{ Health insurance } \\
\hline Insured (Ref) & 4,803 & $69.4(66.5-72.1)$ & 45,472 & $67.6(66.6-68.6)$ & $1.03(0.98-1.07)$ & $0.88(0.83-0.93)^{* *}$ \\
\hline Not insured & 363 & $40.2(31.7-49.3)^{\dagger \dagger}$ & 4,205 & $42.1(39.2-45.1)^{\dagger \dagger}$ & $0.95(0.76-1.20)$ & $0.87(0.72-1.05)$ \\
\hline \multicolumn{7}{|l|}{ Mental health } \\
\hline Excellent, very good, or good (Ref) & 3,866 & $70.7(67.4-73.7)$ & 46,379 & $64.8(63.9-65.8)$ & $1.09(1.04-1.11)^{* *}$ & $0.92(0.86-0.98)^{* *}$ \\
\hline Fair or poor & 1,398 & $56.5(51.2-61.7)^{\dagger \dagger}$ & 4,405 & $61.5(58.2-64.6)^{\dagger \dagger}$ & $0.92(0.83-1.02)$ & $0.79(0.72-0.88)^{* *}$ \\
\hline \multicolumn{7}{|l|}{ Comorbidities ${ }^{\S \S \S}$} \\
\hline No (Ref) & 2,087 & $62.2(57.8-66.4)$ & 37,054 & $60.2(59.2-61.3)$ & $1.03(0.96-1.11)$ & $0.89(0.83-0.96)^{* *}$ \\
\hline Yes & 3,120 & $71.0(67.5-74.3)^{\dagger \dagger}$ & 13,577 & $76.6(74.9-78.2)^{\dagger \dagger}$ & $0.93(0.88-0.98)^{* *}$ & $0.82(0.77-0.88)^{* *}$ \\
\hline \multicolumn{7}{|l|}{ Ever had COVID-19 } \\
\hline No (Ref) & 4,496 & $68.6(65.6-71.5)$ & 43,223 & $68.1(67.1-69.1)$ & $1.01(0.96-1.06)$ & $0.86(0.81-0.91)^{* *}$ \\
\hline Yes & 776 & $59.1(52.3-65.5)^{\dagger \dagger}$ & 7,234 & $49.1(46.9-51.4)^{\dagger \dagger}$ & $1.20(1.06-1.96)^{* *}$ & $1.05(0.93-1.18)$ \\
\hline \multicolumn{7}{|c|}{ Received any vaccine that was not a COVID- 19 vaccine in the past 2 years } \\
\hline Yes (Ref) & 3,224 & $81.1(78.0-83.9)$ & 29,282 & $80.7(79.6-81.7)$ & $1.01(0.97-1.05)$ & $0.90(0.85-0.95)^{* *}$ \\
\hline No & 2,078 & $48.1(43.8-52.4)^{\dagger \dagger}$ & 21,534 & $47.5(46.2-48.8)^{\dagger \dagger}$ & $1.01(0.92-1.11)$ & $0.86(0.78-0.95)^{* *}$ \\
\hline
\end{tabular}

Abbreviations: $\mathrm{Al} / \mathrm{AN}=$ American Indian or Alaska Native; $\mathrm{Cl}=$ confidence interval; $\mathrm{MSA}=$ metropolitan statistical area; $\mathrm{NA}=$ not applicable; $\mathrm{NHPI}=\mathrm{Native} \mathrm{Hawaiian}$ or Other Pacific Islander; Ref = referent group; $\mathrm{SVI}=$ social vulnerability index.

* At least 1 dose of any of the approved COVID-19 vaccines (Pfizer-BioNTech, Moderna, or Janssen [Johnson \& Johnson]).

† Disability was defined as an affirmative response to the following survey question: "Do you have serious difficulty seeing, hearing, walking, remembering, making decisions, or communicating?"

$\S$ Prevalence ratio comparing vaccination rates among persons with a disability with rates among persons without a disability.

" Weighted percentage. Respondents missing either vaccination or disability status were excluded (298).

** $p<0.05$ for prevalence ratio.

${ }^{t+} p<0.05$ by t-test for comparisons of proportions with the indicated reference level.

$\S \S$ White, Black, Al/AN, Asian, NHPI, and multiple-race persons were non-Hispanic; Hispanic persons could be of any race.

१ी Urbanicity derived based on the centroid of the zip code of residence.

*** CDC and Agency for Toxic Substances and Disease Registry Social Vulnerability Index use 15 U.S. Census variables to help officials identify communities that might need support before, during, or after disasters. https://www.atsdr.cdc.gov/placeandhealth/svi/index.html

${ }^{+t+}$ Household income is derived from the number of persons reported in the household, the reported household income, and the 2020 U.S. Census poverty thresholds.

$\S \S \S$ Based on response to the question, “Do you have a health condition that may put you at higher risk for COVID-19?"

scheduling and making vaccination sites more accessible might improve vaccination rates among persons with disabilities (7).

Much work has been done to adapt COVID-19 health messages into more accessible formats ${ }^{\dagger \dagger}$; however, more effort is necessary to increase health equity for persons with disabilities. A recent exploratory analysis of official state and territorial COVID-19 vaccination registration websites found substantial variability and suboptimal compliance with basic accessibility recommendations (8). Information is available for developers of online health information resources and scheduling systems to make web content more accessible. ${ }^{\$ \$}$ Further, online scheduling systems can provide call lines for persons who need assistance making an appointment or requesting assistance

\footnotetext{
$\dagger_{\dagger}$ Accessible COVID-19 vaccine messages adapted from CDC’s full guidance are available at https://cidi.gatech.edu/covid.

$\$ \$$ The Web Accessibility Initiative provides information on making web content accessible. https://www.w3.org/WAI/standards-guidelines/wcag/
}

getting to a vaccination site. CDC recently provided funding to the Administration for Community Living (ACL) to create a national Disability Information and Access Line (DIAL) to assist persons with disabilities obtain a COVID-19 vaccination.99

Even if vaccination locations are identified and appointments are secured, vaccination sites might vary in their accessibility options. All vaccination sites are required to be compliant with the Americans with Disabilities Act; however, regulations do not require that sites have American Sign Language (ASL) interpreters or providers trained to work with persons with intellectual or other developmental disabilities (9). Transportation to a vaccination site might be particularly challenging for persons with a disability who depend on another person to take them or who need accessible vehicles or public transportation. To help overcome some of these challenges,

\footnotetext{
99 Persons with a disability seeking assistance in getting a COVID-19 vaccine can call 888-677-1199, Monday-Friday from 9:00 a.m. to 8:00 p.m. EST or can email DIAL@n4a.org.
} 
FIGURE 1. Age-adjusted prevalence ratios* of COVID-19 vaccine attitudes, perceptions, and recommendations ${ }^{\dagger}$ among adults aged $\geq 18$ years with a disability ${ }^{\S}$ compared with adults without a disability, by COVID-19 vaccination status ${ }^{\mathbb{\eta}}$ - National Immunization Survey Adult COVID Module, United States, May 30-June 26, 2021

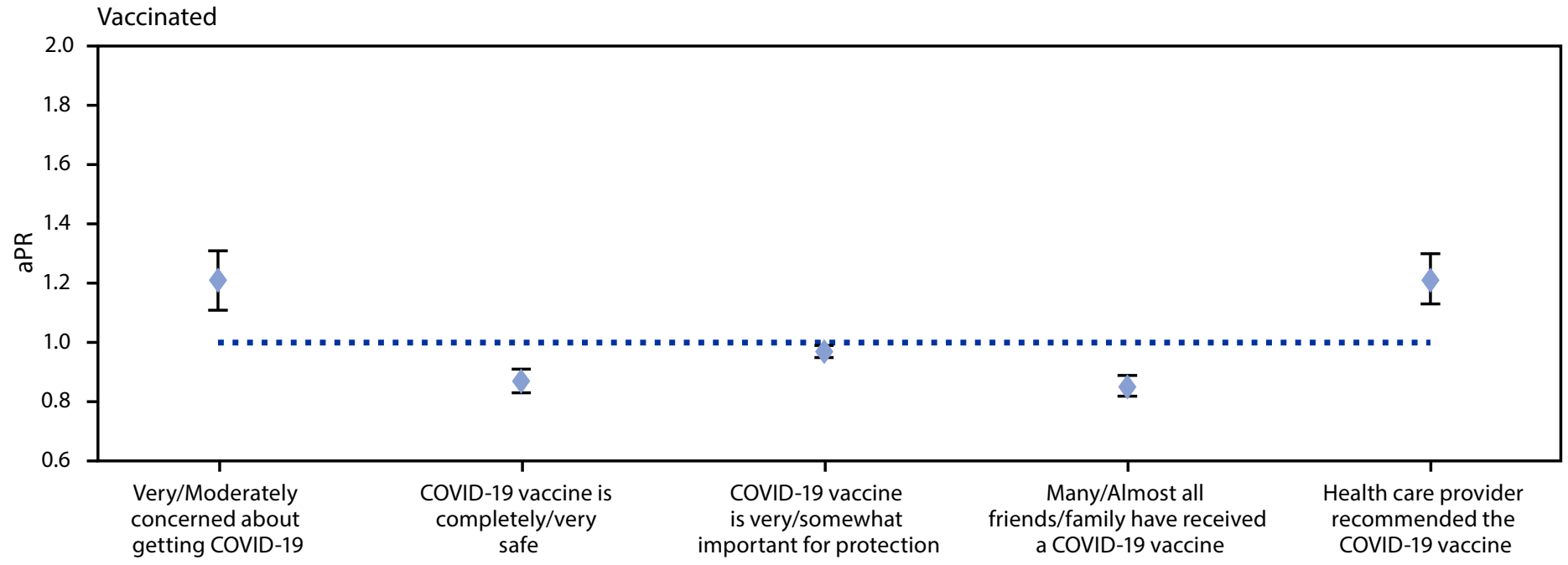

Vaccine attitude/perception/recommendation

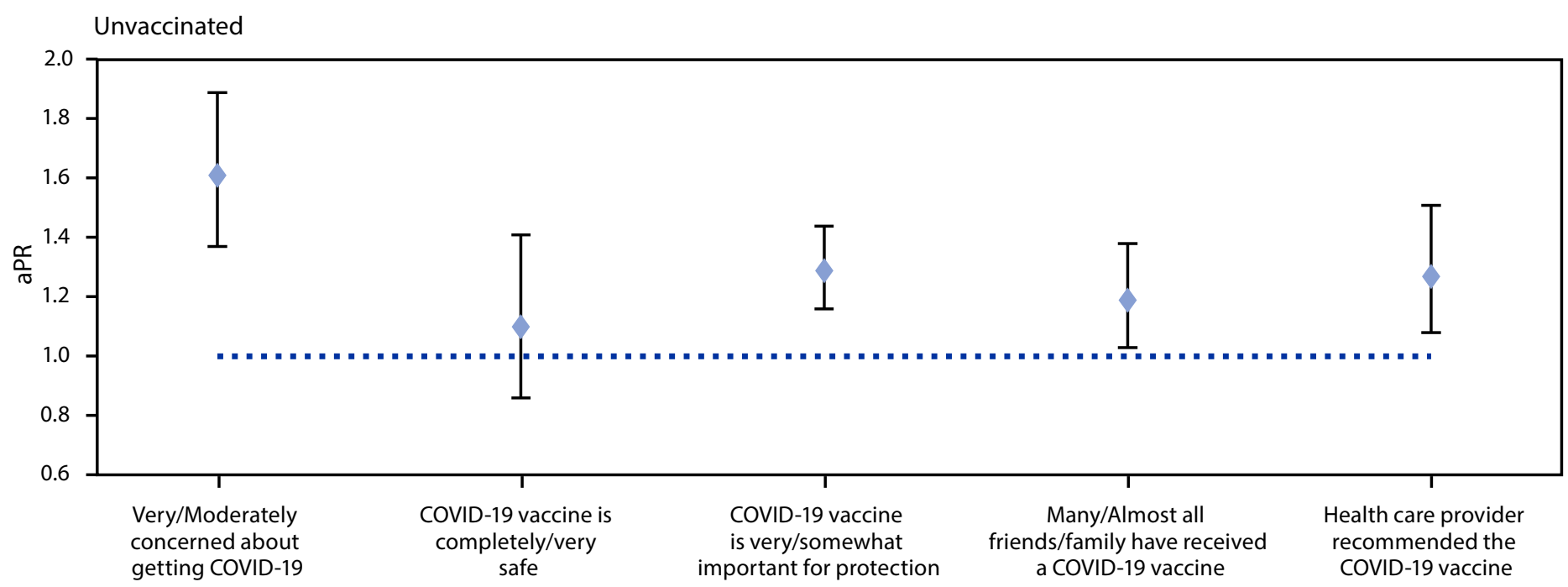

Vaccine attitude/perception/recommendation

Abbreviation: aPR = age-adjusted prevalence ratio.

* 95\% confidence intervals indicated with error bars.

† Prevalence ratio $p<0.05$ for all groups except "unvaccinated: thinks a COVID-19 vaccine is completely/very safe."

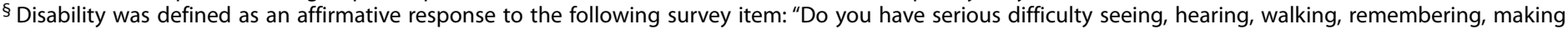
decisions, or communicating?"

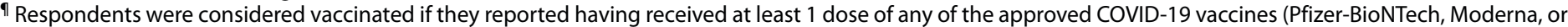
Janssen [Johnson \& Johnson]).

CDC recently provided funding to ACL to provide grants to aging and disability networks in every U.S. state and territory to expand access to COVID-19 vaccination among older adults and persons with disabilities. ${ }^{* * *}$ These grants aid

\footnotetext{
*** https://www.hhs.gov/about/news/2021/03/29/hhs-to-expand-access-tocovid-19-vaccines-for-older-adults-and-people-with-disabilities.html
}

with scheduling vaccination appointments, providing direct support services needed to attend appointments, providing transportation to vaccination sites, and connecting persons who cannot leave their homes independently to in-home vaccination options.

The findings in this report are subject to at least four limitations. First, the low response rate and exclusion of persons 
FIGURE 2. Age-adjusted prevalence ratios* of experiences and difficulties with getting the COVID-19 vaccine ${ }^{\dagger}$ among adults aged $\geq 18$ years with a disability ${ }^{\S}$ compared with adults without a disability, by COVID-19 vaccination status ${ }^{\Uparrow}$ National Immunization Survey Adult COVID Module, United States, May 30-June 26, 2021

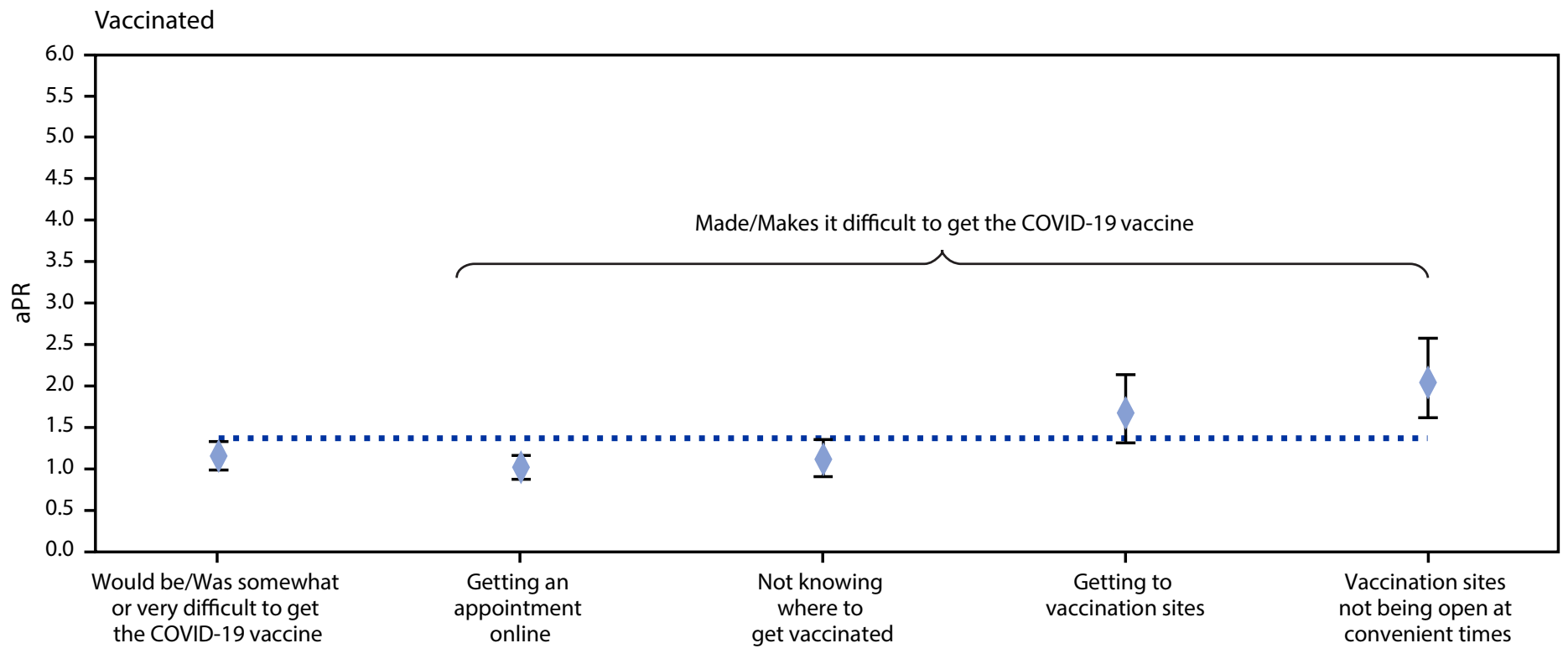

Experiences/Difficulties

Unvaccinated

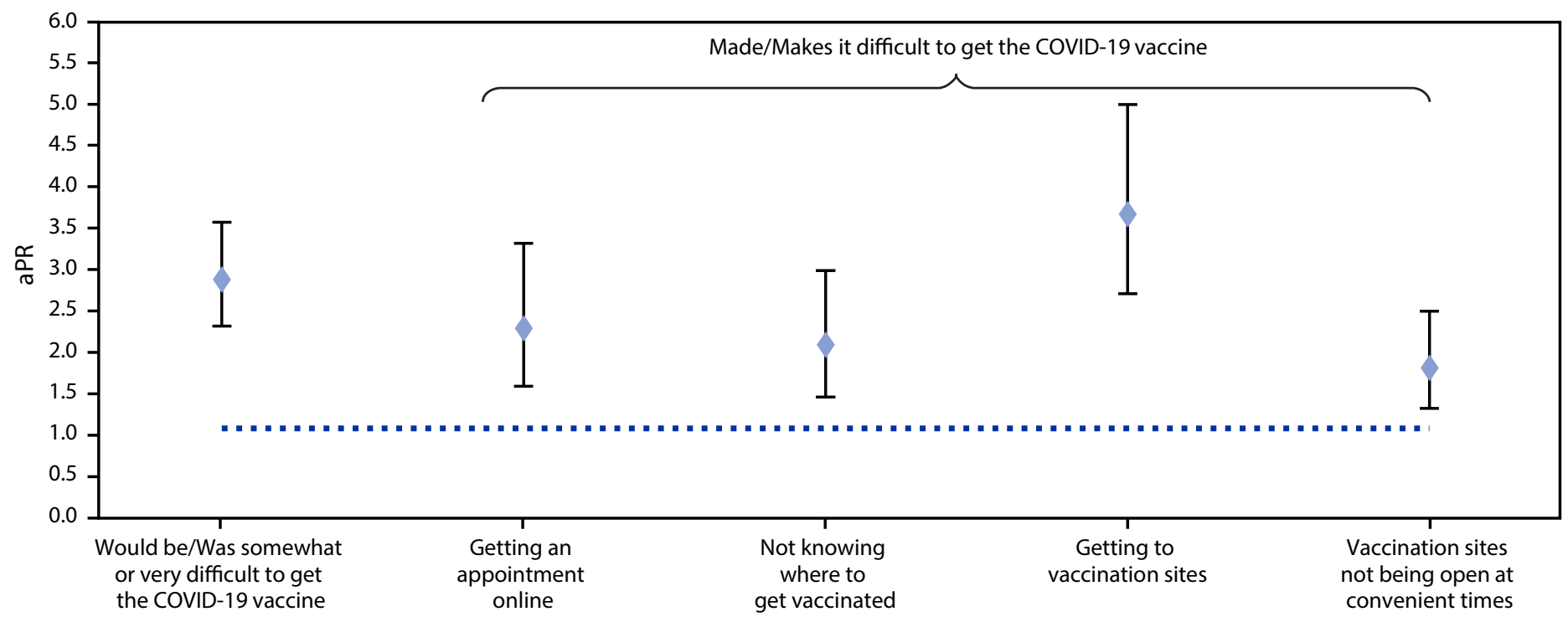

Experiences/Difficulties

Abbreviation: aPR = age-adjusted prevalence ratio.

* $95 \%$ confidence intervals indicated with error bars.

† Prevalence ratio $p<0.05$ for all groups except "vaccinated: getting to vaccination sites."

$\S$ Disability was defined as an affirmative response to the following survey item: "Do you have serious difficulty seeing, hearing, walking, remembering, making decisions, or communicating?"

" Respondents were considered vaccinated if they reported having received at least 1 dose of any of the approved COVID-19 vaccines (Pfizer-BioNTech, Moderna, or Janssen [Johnson \& Johnson]). 
living in institutionalized settings and phoneless or landlineonly households introduces the possibility for selection bias. Estimates of COVID-19 vaccination coverage might differ from vaccine administration and other data reported at https:// covid.cdc.gov/covid-data-tracker/\#vaccinations. ${ }^{\dagger \dagger}$ Second, the question assessing disability status is new and has not been validated or cognitively tested. Approximately $9 \%$ of respondents in the NIS-ACM reported a disability based on the new question, which is lower than the 15\% 2019 ACS estimate for adults using the HHS minimum standard sixquestion set; this variation is likely attributable to multiple factors, including differences in eligibility criteria, survey methods, and questionnaire language. However, even with differing disability prevalence estimates on various national surveys, observed health disparities remain consistent among persons with disabilities (10). Third, attempting to measure this heterogenous demographic group with a single question limits the ability to consider functional type or severity of different disabilities and might obscure differences in access and perceptions of some subgroups. Finally, statistical power is lower to detect differences for persons with a disability than for persons without a disability because of smaller sample sizes.

Public health efforts that make COVID-19 vaccination information, scheduling, and sites more easily accessible for persons with disabilities might help to address health inequities and increase vaccination demand and coverage (7). These include making health messages and vaccination information available in ASL, braille, and easy-to-read formats, making all vaccination sites more accessible to persons of all ability types, including persons with intellectual disabilities and sensory disabilities, and making COVID-19 vaccination available to those who are unable to leave their homes easily or independently. These efforts would be relevant to the reduction of health disparities related to disability beyond the COVID-19 pandemic. Further, regular collection of disability status as a demographic variable in public health surveillance systems can facilitate ongoing monitoring of health disparities among persons with disabilities and help guide understanding of the contextual factors underlying health inequities.

\footnotetext{
部 Estimates of COVID-19 vaccination and intent are also available at https:// covid.cdc.gov/covid-data-tracker/\#vaccinations-disability-status using data from the Census Bureau Household Pulse Survey, and might differ from NIS-ACM estimates. Both data sources indicate lower COVID-19 vaccination coverage among persons with disabilities compared with those without a disability.
}

\section{Summary}

What is already known about this topic?

Persons with disabilities are at increased risk for COVID-19related illness and death.

What is added by this report?

Analysis of the National Immunization Survey Adult COVID Module found that, compared with adults without a disability, those with a disability had a lower likelihood of having received COVID-19 vaccination, despite being less likely to report hesitancy about getting vaccinated. Adults with a disability reported more difficulties obtaining a COVID-19 vaccine than did persons without a disability.

What are the implications for public health practice?

Reducing barriers to scheduling and making vaccination sites more accessible might improve vaccination coverage among persons with disabilities.

\section{Acknowledgments}

A. Elizabeth Allen, Kirk M. Wolter, Adrian Diaz, Nathaniel Poland, Jason Boim, Vicki J. Pineau, Megha Ravanam, Vince Welch, Bess Welch, Amie Conley, Christopher Scott, Maggie Yarbrough, NORC at the University of Chicago; NORC telephone interviewers and supervisory staff members; NIS-ACM survey respondents.

Corresponding author: A. Blythe Ryerson, ztq6@cdc.gov.

\footnotetext{
${ }^{1}$ Division of Human Development and Disability, National Center on Birth Defects and Developmental Disabilities, CDC; ${ }^{2}$ CDC COVID-19 Response Team; ${ }^{3}$ Immunization Services Division, National Center for Immunization and Respiratory Diseases, CDC; ${ }^{4}$ Leidos Inc, Atlanta, Georgia; ${ }^{5}$ Division of Analysis and Epidemiology, National Center for Health Statistics, CDC.
}

All authors have completed and submitted the International Committee of Medical Journal Editors form for disclosure of potential conflicts of interest. Catherine E. Rice reports institutional support to Emory University from the Georgia Department of Public Health, the Georgia Department of Behavioral Health and Developmental Disabilities, NEXT for Autism, National Institute of Mental Health, National Institutes of Health (NIH), and National Institute of Environmental Health Sciences, NIH, outside the submitted work; personal fees for professional training workshops on the diagnostic assessment of autism, outside the submitted work; and participation on advisory boards for the Atlanta Autism Consortium, New Jersey State Scientific Advisory Panel for Autism, HANDS in Autism program. No other potential conflicts of interest were disclosed. 


\section{References}

1. US Census Bureau. 2019 American Community Survey. ACS 1-year estimates subject tables; TableID: S1810. US Department of Commerce, US Census Bureau; 2019. https://data.census.gov/cedsci/table?q=disabil ity\&tid=ACSST1Y2019.S1810

2. Dixon-Ibarra A, Horner-Johnson W. Disability status as an antecedent to chronic conditions: National Health Interview Survey, 2006-2012. Prev Chronic Dis 2014;11:130251. PMID:24480632 https://doi. org/10.5888/pcd 11.130251

3. Okoro CA, Hollis ND, Cyrus AC, Griffin-Blake S. Prevalence of disabilities and health care access by disability status and type among adults-United States, 2016. MMWR Morb Mortal Wkly Rep 2018;67:882-7. PMID:30114005 https://doi.org/10.15585/mmwr. $\mathrm{mm} 6732 \mathrm{a} 3$

4. CDC. COVID-19: people with disabilities. Atlanta, GA: US Department of Health and Human Services, CDC; 2021. Accessed July 25, 2021. https://www.cdc.gov/coronavirus/2019-ncov/need-extra-precautions/ people-with-disabilities.html

5. Turk MA, Landes SD, Formica MK, Goss KD. Intellectual and developmental disability and COVID-19 case-fatality trends: TriNetX analysis. Disabil Health J 2020;13:100942. PMID:32473875 https:// doi.org/10.1016/j.dhjo.2020.100942
6. Office of the Assistant Secretary for Planning and Evaluation. HHS implementation guidance on data collection standards for race, ethnicity, sex, primary language, and disability status. Washington, DC: US Department of Health and Human Services, Office of the Assistant Secretary for Planning and Evaluation; 2021. Accessed July 25, 2021. https://aspe.hhs.gov/reports/hhs-implementation-guidance-datacollection-standards-race-ethnicity-sex-primary-language-disability-0

7. Lau D, Hu J, Majumdar SR, Storie DA, Rees SE, Johnson JA. Interventions to improve influenza and pneumococcal vaccination rates among community-dwelling adults: a systematic review and metaanalysis. Ann Fam Med 2012;10:538-46. PMID:23149531 https://doi. org/10.1370/afm.1405

8. Alismail S, Chipidza W. Accessibility evaluation of COVID-19 vaccine registration websites across the United States. J Am Med Inform Assoc 2021;28:1990-5. PMID:33993310 https://doi.org/10.1093/jamia/ ocab105

9. Americans with Disabilities Act of 1990. Pub. L. 101-336. 104 Stat. 328 (July 26, 1990).

10. Lauer EA, Houtenville AJ. Estimates of prevalence, demographic characteristics and social factors among people with disabilities in the USA: a cross-survey comparison. BMJ Open 2018;8:e017828. PMID:29444777 https://doi.org/10.1136/bmjopen-2017-017828 